\title{
Removal of the left atrium and left ventricle tumour: a case report
}

Stanisław Ostrowski ${ }^{1}$, Anna Marcinkiewicz², Anna Kośmider ${ }^{3}$, Witold Pawłowski ${ }^{1}$, Alicja Nowakowska ${ }^{3}$, Ryszard Jaszewski

\author{
1Department of Cardiac Surgery, $1^{\text {st }}$ Chair of Cardiology and Cardiac Surgery, Medical \\ University of Lodz, Poland \\ 2 Medical student of $5^{\text {th }}$ year, Medical University of Lodz, Poland \\ ${ }^{3}$ Military Teaching Hospital - Veterans Central Hospital, Medical University of Lodz, \\ Poland
}

Submitted: 28 October 2010

Accepted: 13 March 2011

Arch Med Sci 2011; 7, 5: 909-913

DOI: $10.5114 /$ aoms.2011.25571

Copyright (c) 2011 Termedia \& Banach

\section{Corresponding author:}

Stanisław Ostrowski MD, PhD

Department of Cardiac

Surgery

$1^{\text {st }}$ Chair of Cardiology

and Cardiac Surgery

Medical University of Lodz

1/3 Sterlinga

Lodz, Poland

Phone/fax: +48 426331558

E-mail: stanislaw.ostrowski@ umed.lodz.pl

\begin{abstract}
The heart is the rarest site for neoplasms to be localized. Despite modern diagnostic techniques, cardiac tumours continue to among those discovered latest and with the worst prognoses. We present the case of a 62-year-old woman with a heart tumour and mediastinal lymphadenopathy, who was admitted to the Department of Cardiac Surgery. The patient underwent surgical removal of the tumour with extracorporeal circulation. The left atrium, mitral valve and the left ventricle were occupied by the infiltration. A radical resection appeared to be impossible. A valvular prosthesis was not implanted. The perioperative period was uncomplicated. On the $9^{\text {th }}$ day a local recurrence was confirmed in the transthoracic echocardiography. Further oncological diagnostics revealed the spread of the malignant neoplasm to bones of the pelvis and spine. Chemotherapy was initiated. The authors discuss the most appropriate diagnostic and treatment procedures employed in the above case.
\end{abstract}

Key words: heart tumour, lymphadenopathy, radical resection.

\section{Introduction}

Although secondary cardiac tumours occur 20-40 times more frequently than primary ones [1], only $5 \%$ of them are localized in the cardiac muscle [2]. Lung cancer is the most common origin (27\%). As common the heart is involved in the course of breast cancer, lymphomas, leukaemias (10\% in each case) and also in oesophagus cancer (6\%), uterus cancer (5\%) or malignant melanoma (5\%) [3]. Cardiac metastases are generally small and remain clinically silent, especially in the initial period. In the literature there is only a single case of a huge metastasis reported $[4,5]$. Primary cardiac tumours are claimed as a rarity. Their occurrence is estimated at 0.001-0.3\% [6]. Sarcomas are the most common primary malignant heart tumours and if their prevalence is considered they are only less frequent than myxomas [7, 8]. In the author's opinion, the following case provides an interesting example of the pathogenesis and diagnosis of the above issues raised, from both the cardiological and cardiosurgical as well as the oncological point of view. 


\section{Case report}

A 62-year-old woman with a diagnosed heart tumour and lymphadenopathy of the mediastinal lymph nodes was referred to the Cardiosurgery Clinic of the Medical University at Sterlinga Street $1 / 3$ from the $2^{\text {nd }}$ Department and Clinic of Cardiology UM in Lodz.

Two weeks earlier the patient had been admitted to the pulmonary department with symptoms of generalized malaise and a cough, and with a case history of diabetes mellitus type II, arterial hypertension, spine degenerative disease, cholecystolithiasis, past hysterectomy (at the age 48 years) and nodular goitre which was diagnosed histopathologically 3 months earlier the same year. A benign tumour of the right lobe was evident. Physical examination revealed no significant abnormalities. Heart auscultation revealed a systolic murmur. A nodule of the right thyroid lobe was also found. Further examination revealed linear lesions at the base of both lungs, enlarged mediastinal lymph nodes, not grouped in packages, and a nodular structure in the left part of the heart. The patient was consulted cardiosurgically and admission to the clinic was made after urgent cardiological diagnostics with special emphasis on transthoracic echocardiography (TTE).

During the stay in the Clinic of Cardiology, a basic check-up panel was performed, preparing the patient for the planned urgent operation - ECG and coronarography were negative. The cardiac tumour was analysed specifically and verified by transoesophageal echocardiography (TEE). This established the presence of a gelatinous tissue, thickness $10 \mathrm{~mm}$, with a villous surface within the interatrial septum, partially in the left atrium wall. Also located was an additional filamentous structure with length of $14 \mathrm{~mm}$, at the anterior leaflet of the mitral valve from the left atrium site, and a pedunculated, mobile structure, size $4 \mathrm{~cm} \times 2 \mathrm{~cm}$, originating probably from the base of the anterior leaflet. The entire valvular structure was thickened. Moderate IM and mild IT were coexisting. The mass was collapsing into the left ventricular outflow, resulting in blood flow acceleration to $3.5 \mathrm{~m} / \mathrm{s}$ and a maximum gradient through the aortic valve of around $50 \mathrm{mmHg}$. A slight effusion was discovered in the pericardial space. With regard to diagnosed lymphadenopathy, after pulmonary consultation, lymph node excision during cardiosurgical operation was recommended.

The patient was admitted to the Cardiosurgical Clinic with the symptoms of generalised malaise, dizziness and easy fatigue on exertion. For some time the patient had also complained of a pain in the left hip during walking. The stage of euthyreosis was achieved. The removal of the left atrium and left ventricle tumour was carried out with the extracorporeal circulation, in moderate hypothermia $\left(32^{\circ} \mathrm{C}\right)$. Protection of the heart was achieved by a cold crystalloid cardioplegin solution, applied to the aortic bulb. The operation lasted $2 \mathrm{~h}$ and $10 \mathrm{~min}$. The total time of the extracorporeal circulation was $62 \mathrm{~min}$, with the aorta cross-clamped for $48 \mathrm{~min}$. Intraoperatively, the tumour mass was occupying the left atrium, blocking the mitral valve and pulmonary veins ostia. The neoplastic infiltration enclosed the anterior leaflet with a continuation in the left ventricle. The largest possible tumour mass was removed from the left ventricle and left atrium; the pulmonary veins ostia and the mitral valve were also released. Two nodules connected with the anterior leaflet of the mitral valve, which were collapsing to the left ventricle, were also excised. Anterior leaflet plasty was conducted. The enlarged mediastinal lymph nodes were taken for further examination. The tumour structure and localization did not allow for a radical excision, especially in the left ventricle. A decision not to implant the prosthesis instead of the mitral valve was made. The removed biological material was sent for histopathological examination. The postoperative period was uneventful. In the postoperative control echocardiogram a detected recurrence ( 9 th day from the operation) was a mobile, nodular structure, measuring $3.2 \mathrm{~cm} \times 1.8 \mathrm{~cm}$, impeding the blood outflow from the left ventricle and filamentous streak, length $0.9 \mathrm{~cm}$, leading from the middle segment of the anterior mitral leaflet. The haemodynamic parameters were as follows:

- for the aortic valve, maximum gradient $53.5 \mathrm{mmHg}$, maximum blood flow $3.65 \mathrm{~m} / \mathrm{s}$,

- for the mitral valve, respectively $23 \mathrm{mmHg}$ and $2.4 \mathrm{~m} / \mathrm{s}$.

In addition, in the TTE exam mild IA, moderate $I M$ and moderate IT were recorded and enlargement of all heart chambers was noted:

- left atrium $6.3 \mathrm{~cm} \times 5.3 \mathrm{~cm}$,

- left ventricle at systole $4 \mathrm{~cm}$ and at diastole $5.9 \mathrm{~cm}$,

- right atrium $6.2 \mathrm{~cm} \times 4.1 \mathrm{~cm}$,

- right ventricle $2.7 \mathrm{~cm}$.

The systolic function of the heart muscle was evaluated as good with the ejection fraction 55\%, however, it is claimed to be overrated by the mitral insufficiency. A slight pericardial effusion was present. Before surgery, during the additional examination, there was recorded an increased level of inflammatory markers, leukocytosis, C-reactive protein (CRP) and fibrinogen. In the postoperative period there was a significant increase in CRP and with blood cells (WBC) without clinical signs of inflammation. During hospitalization, their levels had gradually decreased, but the value of CRP was eventually not normalized. In the histopathological assessment, including the immunochemistry, the neoplasm was recognized as liposarcoma mostly 


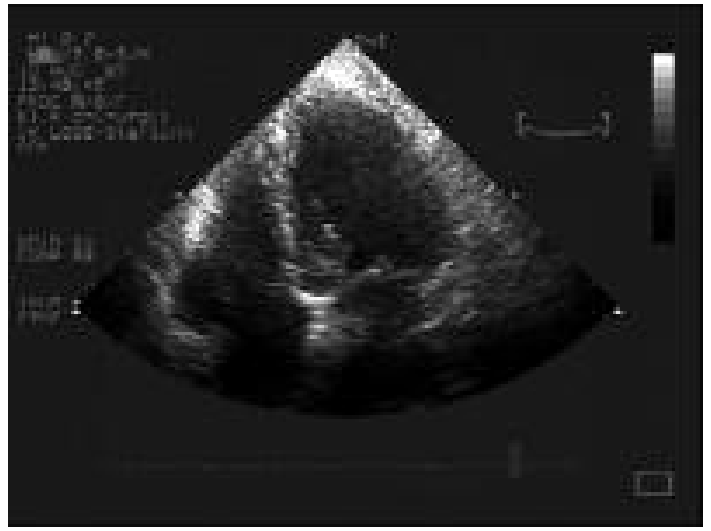

Figure 1. Preoperative echocardiogram

dedifferentiated to undifferentiated sarcoma with a marked mitotic activity of tumour cells. Within the lymph nodes granulation tissue of a sarcoid type was detected.

The patient was referred for consultation and further oncological treatment, during which a neoplastic osteolytic focus measuring $91 \mathrm{~mm} \times 64 \mathrm{~mm}$ in the left ilium bone and pathomorphologically pleomorphic sarcoma malignant fibrous histiocytoma (MFH) was diagnosed. The conducted PET also did not allow exclusion of the presence of a neoplastic focus in the right iliac bone. There were detected metastases in the corpora of vertebrae Th12 and L2 and in the transverse processes of vertebra $L 5$. The patient underwent subsequent cycles of chemotherapy.

Within the 6-month follow-up the patient was hospitalized in the Department of Cardiology of the Medical University of Lodz, due to anemia and exacerbation of the heart failure to NYHA grade 4. The echocardiogram revealed further progression of the cardiac lesions. The tumour had already occupied $1 / 3$ of the left ventricle area. The spreading neoplasm had caused the restriction of the posterior leaflet of the mitral valve and increased the mitral insufficiency to severe. A torn tendinous chorn was detected. In additional tests the CRP had still not been normalized, despite the lack of inflammatory symptoms. After conservative treatment was carried out, achieving an improvement of the morphological parameters, the patient, in NYHA grade $2 / 3$, was discharged from the hospital with a recommendation of further ambulant treatment.

\section{Discussion}

Fibrohistiocytoma can be located in any part of the body [9]. This is the most common soft tissue sarcoma in adults [10], a neoplasm of particularly high malignancy and metastasizing in the early stages of the disease [11]. The mitotic count and nuclear pleomorphism remain the most valuable

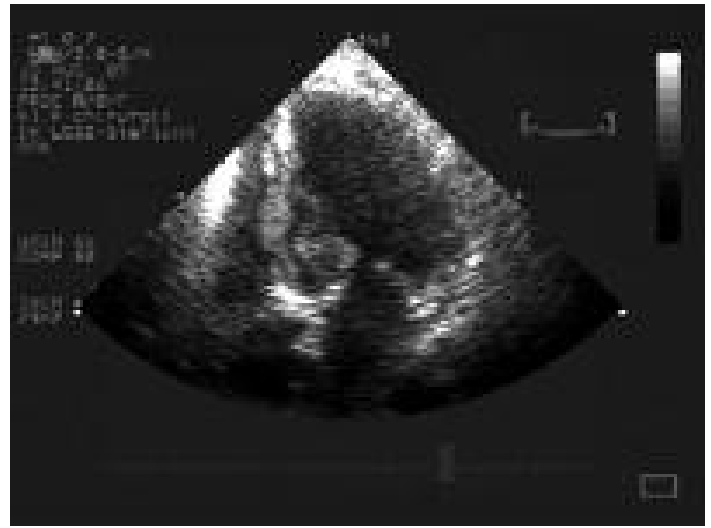

Figure 2. Postoperative echocardiogram with recurrence of the tumour

features for evaluting the sarcoma's advancement [12]. So far, in the literature there have been reported only a few dozen cases of cardiac localization of this sarcoma, while a significant majority arose from the left atrium. To our knowledge, the above-described case is the first in which the sarcoma occupies both the left atrium and the left ventricle. In the literature there are only two reported cases of left ventricular MFH $[13,14]$. The particular localization of the lesion within the heart and, consequently, less specific clinical presentation further delayed the diagnosis, resulting in a highly advanced neoplastic process. Thus the inability to perform complete resection resulted in the rapid development of the recurrence. The TTE and TEE allowed for precise visualization of the intracardiac mass. Computed tomography (CT) and magnetic resonance imaging (MRI) were not done, because the relatively good condition of the patient and the echocardiographic image suggested a benign lesion. Furthermore, the patient was qualified for an urgent operation due to the large size of the tumour resulting in bad haemodynamic parameters. The tumour size was a consequence of a long-lasting growth and a developed compensation. The intraoperative assessment and the rapid local recurrence suggested malignancy, which was histopathologically confirmed. Considering that, the patient was ordered a positron emission tomography (PET) scan to define the primary origin and plan further treatment. On the basis of a poor prognosis and palliative character of the operation, the decision to retain the native valve seemed to be the only suitable procedure. Although a prosthesis or bioprosthesis is usually implanted [15], a rapidly growing tumour mass would be a cause of prosthesis dysfunction and an unavoidable reoperation. Moreover, despite the markedly large tumour mass, the ejection fraction remained fairly good. This suggests the possibility of an 
overstatement of the concomitant mitral regurgitation [16]. Coexisting lymphadenopathy could be a neoplastic reaction [17], but also sarcoidosis cannot be excluded as a distinct clinical entity. Only the lower paratracheal lymph nodes showed increased metabolic activity in the PET examination, which could indicate the presence of cancer cells. The pericardial effusion present in our patient should be considered as a pericardial response [3]. Furthermore, it was also connected with advanced heart failure of grade $3 / 4$. The remaining high level of inflammatory markers should be associated with both the continuing neoplastic process and cardiological disease. Documentary data have reported on the production of cytokines and their free receptors by tumour cells, which decides the systematic inflammatory signs occurrence and increase in inflammatory markers $[6,18]$. Other sources, in turn, refer to the raised CRP level in the course of cardiac diseases, from heart failure to valvular defects [19-22]. It should be taken into consideration that in this case it was an inflammatory syndrome associated directly with paraneoplastic fibrohistiocytoma [23]. Pathogenesis and aetiology of MFH remain unclear. The prognosis is unfavourable, recurrences frequent, and adjuvant therapy ineffective [8]. In our patient it is difficult to identify with full certainty the origin of the tumour. Assuming that the primary lesion was located in the bone, and the diagnosis of fibrohistiocytoma was established, within the tumour tissue found in the heart an increase of the histopathological degree of sarcoma differentiation toward liposarcoma should have occurred. However, according to the histopathological diagnosis of tissue material from the heart, assuming that the primary lesion was located there, the correct diagnosis is liposarcoma, which had dedifferentiated to pleomorphic sarcoma, resembling $\mathrm{MFH}$, and gave metastases. It is worth mentioning that diagnosed in the tissue material, excised from the heart, liposarcoma is one of the tumours most often becoming dedifferentiated. However, the pathomorphological presentation takes on the characteristics of malignant fibrous histiocytoma [24], the selection of which as a distinct nosological entity is currently questionable [25]. Taking into consideration the left-sided tumour location, one would rather suspect the primary cardiac sarcoma, because the right handed tumour location in the heart is more typical of metastases [26]. In the literature, there are only seven cases of primary cardiac sarcoma giving bone metastases [27].

In conclusion, the patient diagnosed and treated in our clinic is an example of a unique tumour localization in the heart chambers and at the base of the anterior leaflet. Previous findings do not suggest, however, considerable differences in the length of survival of patients with malignant tumours, depending on the chosen route of treatment $[28,29]$. Mortality within 8 months after the surgery is estimated at 50\% [3]. Semiannual observation of our patient proves the correctness of the intraoperative decision. It shows effectiveness of the pharmacological and oncological therapy, continued after the surgical procedure. Each case manifesting unspecific symptoms should be subjected to differential diagnosis, including the now widely available tests TTE and TEE. The diagnostics should be followed by $\mathrm{CT}(\mathrm{MRI})$ in reasonable cases.

\section{References}

1. Haponiuk I, Skalski JH, Wronecki K. Guzy serca. In: Kardiochirurgia dziecięca. Skalski JH, Religa Z (eds). Kardiochirurgia szczegółowa wad wrodzonych [Polish]. "Śląsk" Wydawnictwo Naukowe, Katowice 2003; 424-36.

2. Redberg RF. Nowotwory serca. In: Kardiologia. Współczesne rozpoznawanie i leczenie [Polish]. Crawford MH (ed.). 2002; 487-503.

3. Dąbek J, Twardowski R, Jakubowski D, Michniak B, Świderski R, Gąsior Z. Effectiveness of heart tumor therapy in the cardiology department during 7 year follow-up [Polish]. Pol Merk Lek 2009; 27: 362-7.

4. Coller JM, Parente P, Esmore D, New G, Murugasu A, Cooke JC. Large left ventricular metastasis causing left ventricular outflow tract obstruction and haemolysis. Eur J Echocardiogr 2009; 10: 456-8.

5. Zemanek D, Veselka J, Adla T, Setina M, Ferda J. Uncommon cause of obstruction in the left ventricular outflow tract by a metastasis of adenocarcinoma. Arch Med Sci 2010; 6: 981-3.

6. Rivera-Dávila AD, Rodríguez-Ospina L. Primary cardiac and pericardial tumors. Bol Asoc Med PR 2008; 100: 48-54.

7. Kocańda S, Rdzanek A, Filipiak KJ. Pierwotne nowotwory serca [Polish]. Forum Kardiologów 2000; 5: 65-73.

8. Zhang PJ, Brooks JS, Goldblum JR, et al. Primary cardiac sarcomas: a clinicopathologic analysis of a series with follow-up information in 17 patients and emphasis on long-term survival. Hum Pathol 2008; 39: 1385-95.

9. Chuman H. Current topics in the diagnosis and treatment of malignant fibrous histiocytoma. Gan To Kagaku Ryoho 2003; 30: 626-33.

10. Fletcher CD, Gustafson P, Rydholm A, Willén $H$, Akerman M. Clinicopathologic re-evaluation of 100 malignant fibrous histiocytomas: prognostic relevance of subclassification. J Clin Oncol 2001; 19: 3045-50.

11. Sheikh AA, Ahmad M, Lone AR, Banday MA. Cardiac metastasis in malignant fibrous histiocytoma. Saudi Med J 2008; 29: 1041-3.

12. Karolewski K, Gliński B, Jakubowicz J, et al. Uterine sarcomas - an evaluation of treatment results and prognostic factors. Arch Med Sci 2009; 5: 215-21.

13. Fang CY, Fu M, Chang JP, Eng HL, Hung JS. Malignant fibrous histiocytoma of the left ventricle: a case report. Changgeng Yi Xue Za Zhi 1996; 19: 187-90.

14. Chung TJ, Cheng L, Yu CY. Left ventricular malignant fibrous histiocytoma. Clin Imaging 2007; 31: 422-4.

15. Sakata K, Oktaki A, Aiba M, et al. Left ventricular fibroma in an aged patient: report of a case. Surg Today Jpn J Surg 1997; 27: 88-9. 
16. Browarek A, Leszek P. The assessment of left ventricular function including low-dose dobutamine echocardiography in patients with chronic mitral insufficiency before and after mitral valve replacement [Polish]. Folia Cardiol 2003; 10: 667-74.

17. Dubaniewicz A. Sarkoidoza - choroba o wielu twarzach. Wybrane problemy kliniczne [Polish]. Forum Medycyny Rodzinnej 2009; 3: 27-41.

18. Kamińska J, Kowalska M, Kotowicz B, Fuksiewicz M. The prognostic value of cytokine levels in patients with cancer. Wspolczesna Onkol 2006; 10: 259-62.

19. Anand IS, Latini R, Florea VG, et al. C-reactive protein in heart failure: prognostic value and the effect of valsartan. Circulation 2005; 112: 1428-34.

20. Gibas M, Miszczak-Śmiałek J. Zapalne podłoże miażdżycy - kliniczna użyteczność oznaczania białka C-reaktywnego [Polish]. Wiad Lek 2006; 59: 242-5.

21. Galante A, Pietroiusti A, Vellini M, et al. C-reactive protein is increasedin patients with degenerative aortic valvular stenosis. J Am Coll Cardiol 2001; 38: 1078-82.

22. Harikrishnan S, Rajeev E, Jaganmohan A, et al. Acute phase reactans predict mitral regurgitation following mitral valvuloplasty. Int J Cardiol 2006; 112: 127-9.

23. Nakanishi H, Araki N, Kudawara I, et al. Clinical implications of serum C-reactive protein levels in malignant fibrous histiocytoma. Int J Cancer 2002; 99: 167-70.

24. Fletcher CD. The histological features of local recurrences of soft tissue sarcomas. Pathologe 1994; 15: 196-200.

25. Fletcher CDM, Gustafson P, Rydholm A, Willén H, Åkerman M. Clinicopathologic re-evaluation of 100 malignant fibrous histiocytomas: prognostic relevance of subclassification. J Clin Oncol 2001; 19: 3045-50.

26. Yu K, Liu Y, Wang H, Hu S, Long C. Epidemiological and pathological characteristics of cardiac tumors: a clinical study of 242 cases. Interact Cardiovasc Thorac Surg 2007; 6: 636-9.

27. Strina C, Zannoni M, Parolin V, Cetto GL, Zuliani S. Bone metastases from primary cardiac sarcoma: case report. Tumori 2009; 95: 251-3.

28. Dąbek J, Monastyrska-Cup B, Jakubowski D, Szulc A, Gąsior Z. Neoplastic tumor of the right ventricle of the heart - a case report [Polish]. Chir Pol 2007; 1: 51-6.

29. Kobayaski M, Okabayaski T, Okamoto K, Namikowa T, Araki K. Clinicopathological study of cardiac tamponade due to pericardial metastasis originating from gastric cancer. World J Gastroenterol 2005; 11: 6899-904. 